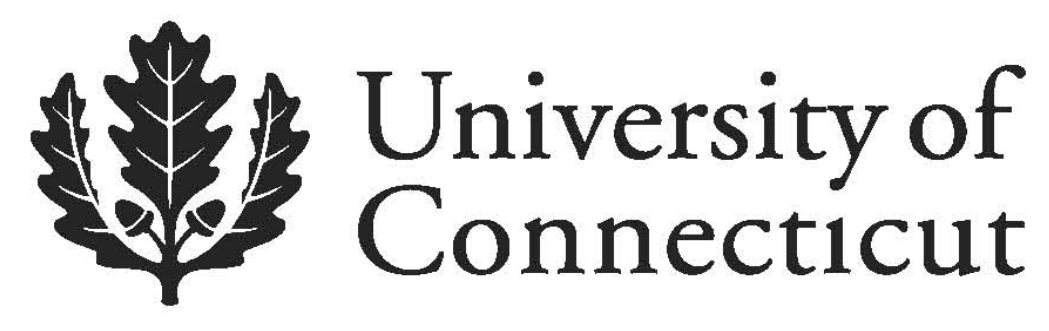

Department of Economics Working Paper Series

\title{
Real Exchange Rate Fluctuations, Wage Stickiness and Tradability
}

Yothin Jinjarak

University of London

Kanda Naknoi

University of Connecticut

Working Paper 2013-01

February 2013

365 Fairfield Way, Unit 1063

Storrs, CT 06269-1063

Phone: (860) 486-3022

Fax: (860) 486-4463

http://www.econ.uconn.edu/

This working paper is indexed on RePEc, http://repec.org 


\title{
Real Exchange Rate Fluctuations,
}

\section{Wage Stickiness and Tradability *}

\author{
Yothin Jinjarak ${ }^{\dagger}$ \\ University of London
}

\author{
Kanda Naknoi ${ }^{\ddagger}$ \\ University of Connecticut
}

This draft: February 2013

First draft: April 2009

\begin{abstract}
This study constructs a new measure of nontradability of goods and demonstrates that it can explain the sectoral heterogeneity of the variance of sector-specific real exchange rate depreciation. Our measure of nontradability is the share of labor costs, including those incurred in the production of intermediate inputs. In the empirical analysis, we employ monthly data of US-Canada sector pairs and quarterly data of US-Germany sector pairs. We found that, for a certain range of nontradability, an increase in the degree of nontradability raises the variance of sector-specific real exchange rate depreciation. In addition, an increase in the degree of nontradability raises the fraction of variance of sector-specific real exchange rate depreciation accounted for by wage inflation differentials.
\end{abstract}

JEL codes: F41, F42

Keywords: real exchange rate; wage stickiness; tradability

${ }^{*}$ We would like to thank two anonymous referees, Yin-Wong Cheung, Mario Crucini, David Hummels, Chong

Xiang and participants in Purdue Brownbag seminar, the 2009 APEA Meeting, the 2009 SERC Conference and the 2010 Midwest Macro Meeting for comments.

${ }^{\dagger}$ Department of Financial and Management Studies, SOAS, University of London, London WC1H 0XG, UK;

yj5@soas.ac.uk

${ }^{\ddagger}$ Department of Economics, University of Connecticut, 365 Fairfield Way, Unit 1063, Storrs, CT 06269-1063;

Email: kanda.naknoi@uconn.edu. 


\section{Introduction}

The literature on the real exchange rate (RER) has documented the importance of the degree of tradability of goods as a determinant of short-run movements of RERs. Betts and Kehoe (2006) measured tradability by the ratio of trade to output and found that tradability has a negative effect on RER volatility of industrialized countries. In Burstein, Neve and Rebelo (2003) and Burstein, Eichenbaum and Rebelo (2005), tradability is determined by distribution costs. They demonstrated that distribution costs have a positive effect on the RER volatility following an exchange-rate-based stabilization policy. Ghironi and Melitz (2005) and Naknoi (2008) defined tradability as the endogenous set of traded goods and illustrated that the short-run adjustment in tradability offers an explanation for the variance decomposition of RERs in Engel (1999) and Mendoza (2000). The recent study on deviations from the law of one price (LOOP) by Crucini, Telmer and Zachariadis (2005) found that the share of nontraded intermediate inputs is positively related to cross-sectional price dispersion in European data. In addition, Crucini and Shintani (2008) found a positive cross-sectional relationship between LOOP persistence and the distribution margin.

Our study proposes an alternative measure of tradability and examines its influence on the volatility of deviations from the LOOP or sector-specific RER depreciation. While tradability of goods is determined by tradability of inputs, as in Burstein et al. (2003), Burstein et al.(2005) and Crucini et al. (2005), our focus is not the cost of nontraded intermediate inputs, but rather the cost of labor in the entire process of production. Our approach is motivated by the notion that nontraded goods are labor intensive. However, the literature has not incorporated labor costs into the empirical measure of tradability. We integrate the role of labor costs and make the following 
three contributions to the literature.

First, we derive our measure of nontradability from a cost accounting that incorporates crosssector interdependence in the production structure of the input-output table. Final goods are produced from labor, capital and intermediate inputs. A fraction of intermediate inputs is imported. Domestic production of intermediate goods requires labor, capital and other intermediate goods. This structure of production implies that all final goods embed immobile labor, therefore all final goods contain nontraded inputs, as argued by Jones and Sanyal (1982). We assume that wholesalers and retailers have monopoly power and charge markups. We then decompose the bilateral sector-specific RER depreciation into two components: (1) the bilateral difference in wage inflation relative to an increase in the cost of capital, weighted by the share of labor costs in total costs, and (2) a weighted average of the deviation from the LOOP for relatively mobile factors (imported intermediates and capital), and the bilateral difference in markup adjustments. We propose that the weight attached to the first component, namely the share of labor costs in total costs, can serve as a measure of nontradability. Our measure of nontradability is increasing in the cost share of labor at each stage of production, and increasing in the share of nontraded intermediate inputs. Hence, our approach highlights the role of labor costs without contradicting the previous study by Crucini et al. (2005).

Second, we demonstrate that, theoretically, our degree of nontradability is a determinant of the time-series variance of sector-specific RER depreciation. We disaggregate the bilateral sectorspecific RER depreciation into a sum of the exchange rate-adjusted wage inflation differential weighted by the degree of nontradability and the residual. The residual is a linear combination of the deviation from the LOOP for imported intermediate inputs and capital, and the bilateral difference in markup adjustments. Hence, in theory there is a quadratic relationship between the 
degree of nontradability and the second moment of sector-specific RER depreciation. In addition, the fraction of variance of sector-specific RER depreciation accounted for by wage inflation differentials is determined by the degree of nontradability, among other factors.

Finally, we provide empirical evidence that our degree of nontradability explains sectoral heterogeneity of the time-series variance of sector-specific RER depreciation and its fraction of which is accounted for by wage inflation differentials, as suggested by our theoretical framework. We employ monthly data of 36 sectors in the US and Canada from January 1991 to January 2009, and quarterly data of 31 sectors in the US and Germany from the first quarter in 1995 to the fourth quarter in 2006. We calculate the share of labor in total costs from the US input-output table. In addition to the degree of nontradability, our dataset has time series of sector-specific prices, sector-specific wages and exchange rates, hence we can calculate changes in relative prices and relative wages over various time horizons. We measure changes over horizons from one month to 24 months for US-Canada sector pairs, and from one quarter to eight quarters for US-Germany sector pairs.

There are four empirical findings. First, wage inflation differentials account for $0 \%-72 \%$ of the time-series variance of US-Canada sector-specific RER depreciation, depending on the time horizon. The corresponding number for the US-Germany pairs is $0 \%-56 \%$. The median contribution of wage inflation differentials to the variance of sector-specific RER depreciation is roughly $30 \%$ in both samples. This finding is consistent with the observed time-series correlation between sectorspecific RER depreciation and wage inflation differentials. The correlation for US-Canada sector pairs varies from $40 \%$ to $78 \%$, depending on the time horizon. For US-Germany sector pairs, the correlation is over $90 \%$ for all horizons. This finding is a departure from the empirical literature on RER variance decomposition, such as Engel (1999). In that literature, the US-Canada RER 
depreciation and the US-Germany RER depreciation are found to be driven almost $100 \%$ by deviations from the LOOP for traded goods.

Second, we found a quadratic relationship between the degree of nontradability and the variance of sector-specific RER depreciation over a 24-month horizon for US-Canada sector pairs, and 4-quarter and 8-quarter horizons for US-Germany sector pairs. The quadratic relationship suggests that a positive effect of the degree of nontradability on the variance of sector-specific RER depreciation depends on the minimum threshold level of nontradability. Our estimated coefficients imply that, conditioning on passing the threshold level, a one-standard deviation increase in the degree of nontradability raises the variance of sector-specific RER depreciation by roughly $40 \%$ of its dispersion for US-Canada sector pairs over a 24-month horizon and US-Germany sector pairs over a 8-quarter horizon, and 34\% of its dispersion for US-Germany pairs over a 4-quarter horizon.

Third, we found that the degree of nontradability has a positive effect on the contribution of wage inflation differentials to the variance of sector-specific RER depreciation over all horizons. In terms of scale, a one-standard deviation increase in the degree of nontradability raises the contribution of wage inflation differentials to the variance of sector-specific RER depreciation by 8\%-9\% for US-Canada sector pairs, and 8\%-11\% for US-Germany sector pairs. An alternative interpretation is that, a one-percent increase in the degree of nontradability raises the contribution of wage inflation differentials to the sector-specific RER depreciation by roughly three quarters of a percent.

Finally, when we replace our measure of nontradability with the share of nontraded intermediate inputs obtained from a similar methedology to Crucini et al. (2005), we also found a quadratic relationship between the share of nontraded intermediate inputs and the variance of sector-specific RER depreciation. The quantitative effect of the share of nontraded intermediates on the variance 
of sector-specific RER depreciation is found to be smaller than the effect of the degree of nontradability in the case of US-Canada sector pairs, but larger in the case of US-Germany sector pairs. However, we found no relationship between the share of nontraded intermediate inputs and the contribution of wage inflation differentials to the variance of sector-specific RER depreciation.

Our work is related to the literature on the border effect, such as Engel and Rogers (1996), who suggest that price stickiness and wage stickiness are the main causes of deviations from the LOOP. The economic significance of wage inflation differentials in our study highlights the role of wage stickiness, which arises in the presence of labor market frictions that prevent labor from moving across countries and sectors. This aspect of our work contributes to the growing literature that emphasizes the importance of labor market frictions in open economies, such as Kehoe and Ruhl (2009) and Mendoza, Tesar and Gorodnichenko (2008). The key difference is that we highlight the importance of sectoral heterogeneity of labor market frictions rather than aggregate frictions. Our study also offers indirect evidence of wage stickiness and supplements the studies on wage stickiness in a closed-economy framework (Castellanos et al., 2004; Kahn, 1997; Liu and Phaneuf, 2007; Taylor, 1999).

Section 2 outlines the methodology. The description of data and empirical results are in Section 3. Section 4 concludes.

\section{Methodology}

\subsection{Cost Accounting}

For the purpose of exposition, first we consider two sectors and subsequently we incorporate a large number of sectors. Let a subscript $i$ denote sectors, where $i=1,2$. Good $i$ is produced from labor, 
capital and intermediate input $j$ with a Cobb-Douglas technology. A fraction of intermediate input $j$ is imported. Let the cost share of labor in the production of good $i$ be $\alpha_{i}\left(0<\alpha_{i}<1\right)$. The cost share of domestically produced intermediate input $j$ and that of imported intermediate input $j$ are $\delta_{i}\left(0<\delta_{i}<1\right)$ and $\beta_{i}\left(0<\beta_{i}<1\right)$, respectively. Let $t$ denote time. For simplicity, assume that the intermediate good market is perfectly competitive. Thus, the price of intermediate good $i$ is its marginal cost:

$$
P_{d i t}=a_{i} W_{i t}^{\alpha_{i}} P_{d j t}^{\delta_{i}} P_{m j t}^{\beta_{i}} R_{i t}^{1-\alpha_{i}-\delta_{i}-\beta_{i}}
$$

where $a_{i}=\left(\alpha_{i}^{\alpha_{i}} \delta_{i}^{\delta_{i}} \beta_{i}^{\beta_{i}}\left(1-\alpha_{i}-\delta_{i}-\beta_{i}\right)^{1-\alpha_{i}-\delta_{i}-\beta_{i}}\right)^{-1}$. $W_{i t}$ is the nominal wage in sector $i, P_{d j t}$ is the price of domestically produced intermediate input $j, P_{m j t}$ is the price of imported intermediate input $j$, and $R_{i t}$ is the cost of capital in sector $i$. Likewise, the marginal cost of intermediate good $j$ takes a similar form. Substituting the marginal cost of intermediate good $j$ into (1) gives the price of domestically produced intermediate $\operatorname{good} i$ :

$$
P_{d i t}=a_{i} a_{j}^{\delta_{j}} W_{i t}^{\alpha_{i}} W_{j t}^{\delta_{i} \alpha_{j}} P_{d i t}^{\delta_{i} \delta_{j}} P_{m i t}^{\delta_{i} \beta_{i}} R_{j t}^{\delta_{i}\left(1-\alpha_{j}-\delta_{j}-\beta_{j}\right)} P_{m j t}^{\beta_{j}} R_{i t}^{1-\alpha_{i}-\delta_{i}-\beta_{i}}
$$

Note that the price of domestically produced intermediate good $i$ in equation (2) includes its own price, because its production requires input from its own sector $i$ as well as from the other sector $j$, as in the production structure in the input-output table. Consequently, (2) yields the following price of domestically produced intermediate good $i$ :

$$
P_{d i t}=a_{i} a_{j}^{\frac{\delta_{j}}{1-\delta_{i} \delta_{j}}} W_{i t}^{\frac{\alpha_{i}}{1-\delta_{i} \delta_{j}}} W_{j t}^{\frac{\delta_{i} \alpha_{j}}{1-\delta_{i} \delta_{j}}} P_{m i t}^{\frac{\delta_{i} \beta_{j}}{1-\delta_{i} \delta_{j}}} R_{j t}^{\frac{\delta_{i}\left(1-\alpha_{j}-\delta_{j}-\beta_{j}\right)}{1-\delta_{i} \delta_{j}}} P_{m j t}^{\frac{\beta_{i}}{1-\delta_{i} \delta_{j}}} R_{i t}^{\frac{1-\alpha_{i}-\delta_{i}-\beta_{i}}{1-\delta_{i} \delta_{j}}}
$$


Finally, the retailer distributes the final good $i$ to consumers by charging the distribution markup $\mu_{i t}\left(\mu_{i t} \geq 1\right)$ over the price of intermediate good $i$ in (3). Hence, the price of final good $i$ is:

$$
P_{i t}=\mu_{i t} a_{i} a_{j}^{\frac{\delta_{j}}{1-\delta_{i} \delta_{j}}} W_{i t}^{\frac{\alpha_{i}}{1-\delta_{i} \delta_{j}}} W_{j t}^{\frac{\delta_{i} \alpha_{j}}{1-\delta_{j} \delta_{j}}} P_{m i t}^{\frac{\delta_{i} \beta_{j}}{1-\delta_{i} \delta_{j}}} R_{j t}^{\frac{\delta_{i}\left(1-\alpha_{j}-\delta_{j}-\beta_{j}\right)}{1-\delta_{i} \delta_{j}}} P_{m j t}^{\frac{\beta_{i}}{1-\delta_{i} \delta_{j}}} R_{i t}^{\frac{1-\alpha_{i}-\delta_{i}-\beta_{i}}{1-\delta_{i} \delta_{j}}}
$$

\subsection{Sector-Specific Real Exchange Rate}

Define the sector-specific RER as $Q_{i t}=\left(S_{t} P_{i t}^{\star}\right) / P_{i t}$, where $S_{t}$ represents units of the home currency per unit of the foreign currency, and the superscript $\star$ denotes foreign variables. We assume that technology and market structure in the two countries are identical. Substituting the retail price in (4) into the definition of RER gives the following expression:

$$
Q_{i t}=M_{i t}\left(\frac{S_{t} W_{i t}^{\star}}{W_{i t}}\right)^{\gamma_{i}}\left(\frac{S_{t} P_{m i t}^{\star}}{P_{m i t}}\right)^{\lambda_{i}}\left(\frac{S_{t} R_{i t}^{\star}}{R_{i t}}\right)^{1-\gamma_{i}-\lambda_{i}}
$$

where

$$
\begin{aligned}
M_{i t}= & \frac{\mu_{i t}^{\star}\left(W_{j t}^{\star} / W_{i t}^{\star}\right)^{\frac{\delta_{i} \alpha_{j}}{1-\delta_{i} \delta_{j}}}\left(R_{j t}^{\star} / R_{i t}^{\star}\right)^{\frac{\delta_{i}\left(1-\alpha_{j}-\delta_{j}-\beta_{j}\right)}{1-\delta_{i} \delta_{j}}}\left(P_{m j t}^{\star} / P_{m i t}^{\star}\right)^{\frac{\beta_{j}}{1-\delta_{i} \delta_{j}}}}{\mu_{i t}\left(W_{j t} / W_{i t}\right)^{\frac{\beta_{j} \alpha_{j}}{1-\delta_{i} \delta_{j}}}\left(R_{j t} / R_{i t}\right)^{\frac{\delta_{i}\left(1-\alpha_{j}-\delta_{j}-\beta_{j}\right)}{1-\delta_{i} \delta_{j}}}\left(P_{m j t} / P_{m i t}\right)^{\frac{\beta_{j}}{1-\delta_{i} \delta_{j}}}} \\
\gamma_{i}= & \frac{\alpha_{i}+\delta_{i} \alpha_{j}}{1-\delta_{i} \delta_{j}} \\
\lambda_{i}= & \frac{\beta_{i}+\delta_{i} \beta_{j}}{1-\delta_{i} \delta_{j}}
\end{aligned}
$$

$M_{i t}$ represents the foreign distribution markup relative to the domestic distribution markup, adjusted by foreign-domestic ratio of the cross-sector difference in factor prices.

Next, let us denote natural logarithm by a lowercase. We define exchange rate-adjusted wage differentials in sector $i$ as $\omega_{i t}=s_{t}+w_{i t}^{\star}-w_{i t}$. Henceforth, we refer to this variable as wage 
differentials. We define relative price of imported intermediate input $i$ as $\psi_{i t}=s_{t}+p_{m i t}^{\star}-p_{m i t}$, and relative cost of capital in sector $i$ as $\kappa_{i t}=s_{t}+r_{i t}^{\star}-r_{i t}$. Let $\Delta$ denote the first difference. Thus, first differencing the RER in equation (5) gives the sector-specific RER depreciation as follows:

$$
\Delta q_{i t}=\Delta m_{i t}+\gamma_{i} \Delta \omega_{i t}+\lambda_{i} \Delta \psi_{i t}+\left(1-\gamma_{i}-\lambda_{i}\right) \Delta \kappa_{i t}
$$

Intuitively, fluctuations in sector-specific RERs are driven by the bilateral difference of changes in markups and the bilateral difference of cost changes weighted by the cost share for each factor of production.

Alternatively, we can write the sector-specific RER depreciation in (6) as follows:

$$
\Delta q_{i t}=\gamma_{i}\left[\left(\Delta w_{i t}^{\star}-\Delta r_{i t}^{\star}\right)-\left(\Delta w_{i t}-\Delta r_{i t}\right)\right]+\left[\lambda_{i t} \psi_{i t}+\left(1-\lambda_{i}\right) \kappa_{i t}\right]+\Delta m_{i t}
$$

According to (7), the sector-specific RER depreciation is decomposed into three components: (i) the bilateral difference in wage inflation relative to an increase in the cost of capital, (ii) the deviation from the law of one price for imported intermediate input and capital, and (iii) the bilateral difference in markup adjustments. The decomposition in (7) is the sector analog of the decomposition of country-level RER depreciation in Engel (1999), Mendoza (2000) and Naknoi (2008). In these studies, the country-level RER depreciation $\left(\Delta q_{t}\right)$ is decomposed into the bilateral difference in inflation of nontraded goods relative to traded goods (nontraded RER depreciation or $\Delta q_{N t}$ ) and the deviation from the law of one price for traded goods (traded RER depreciation or $\left.\Delta q_{T t}\right)$ :

$$
\Delta q_{t}=s_{N} \Delta q_{N t}+\Delta q_{T t}
$$


where $\Delta q_{N t}=\left(\Delta p_{t N}^{\star}-\Delta p_{T t}^{\star}\right)-\left(\Delta p_{N t}-\Delta p_{T t}\right)$ and $\Delta q_{T t}=\Delta s_{t}+\Delta p_{T t}^{\star}-\Delta p_{T t}$. The parameter $s_{N}$ is the expenditure share of nontraded goods and $0<s_{N}<1$. The variables $p_{N t}$ and $p_{T t}$ denote the natural logarithm of the price index of the nontraded-goods basket and that of the traded-goods basket, respectively.

Provided that the bilateral difference in wage inflation relative to an increase in the cost of capital, or $\left[\left(\Delta w_{i t}^{\star}-\Delta r_{i t}^{\star}\right)-\left(\Delta w_{i t}-\Delta r_{i t}\right)\right]$ in (7) represents the nontraded component of sectorspecific RER depreciation, the weight of this nontraded component or $\gamma_{i}$ can be used as a measure of the sector-specific degree of nontradability.

\subsection{Sector-Specific Degree of Nontradability}

Without loss of generality, we can incorporate the above analysis with a large number of sectors $N$, where $N>2$. In this case, the degree of nontradability takes a similar form:

$$
\gamma_{i}=\frac{\alpha_{i}+\delta_{i} \alpha_{j}}{1-\delta_{i} \delta_{j}}
$$

where $\alpha_{j}$ is the share of labor in the total cost of production of all domestic intermediates $j, j \neq i$, and $\delta_{j}$ is the share of domestic intermediates in the total cost of production of all intermediates $j, j \neq i$. Hence, the product $\delta_{i} \alpha_{j}$ captures the cost share of labor embedded in domestic intermediates from all other sectors. The denominator $1-\delta_{i} \delta_{j}$ reflects the use of intermediate goods $i$ and $j, j \neq i$, in the production of final good $i$.

Essentially, the degree of nontradability rises when the share of labor in total costs rises in any sector, as production of an intermediate good requires domestic intermediates from all other sectors. In addition, the degree of nontradability rises when the share of domestic intermediate 
inputs in total cost rises in any sector, as production of any domestic intermediates requires labor.

This result is consistent with the finding in Burstein et al. (2003, 2005) and Crucini et al. (2005) that the share of nontraded intermediate inputs in total costs is a determinant of nontradability.

\subsection{Variance of Sector-Specific Real Exchange Rate Depreciation}

As an empirical strategy, we combine the bilateral difference in markup adjustment and the deviation from the LOOP for imported intermediates and capital as the residual term:

$$
\Delta h_{i t}=\Delta m_{i t}+\lambda_{i} \Delta \psi_{i t}+\left(1-\gamma_{i}-\lambda_{i}\right) \Delta \kappa_{i t}
$$

Then, the sector-specific RER depreciation becomes

$$
\Delta q_{i t}=\gamma_{i} \Delta \omega_{i t}+\Delta h_{i t}
$$

Let $\sigma_{i}^{w}$ and $\sigma_{i}^{h}$ denote the standard deviation of $\Delta \omega_{i t}$ and $\Delta h_{i t}$, respectively. Also, let $\rho_{i}^{w h}$ denote the correlation between $\Delta \omega_{i t}$ and $\Delta h_{i t}$. The time-series variance of the sector-specific RER depreciation in equation 10 is

$$
\left(\sigma_{i}^{q}\right)^{2}=\gamma_{i}^{2}\left(\sigma_{i}^{w}\right)^{2}+2 \gamma_{i} \rho_{i}^{w h} \sigma_{i}^{w} \sigma_{i}^{h}+\left(\sigma_{i}^{h}\right)^{2}
$$

Denote the contribution of wage inflation differentials to the variance of RER depreciation in (11) with

$$
v_{w}^{i}=\frac{\gamma_{i}^{2}\left(\sigma_{i}^{w}\right)^{2}+\gamma_{i} \rho_{i}^{w h} \sigma_{i}^{w} \sigma_{i}^{h}}{\gamma_{i}^{2}\left(\sigma_{i}^{w}\right)^{2}+2 \gamma_{i} \rho_{i}^{w h} \sigma_{i}^{w} \sigma_{i}^{h}+\left(\sigma_{i}^{h}\right)^{2}} .
$$




\subsection{Estimating Equations}

We obtain the first estimating equation from the variance of sector-specific RER depreciation in (11):

$$
\left(\sigma_{i}^{q}\right)^{2}=a_{0}+a_{1} \gamma_{i}^{2}+a_{2} \gamma_{i}+\epsilon_{i}
$$

This quadratic specification is useful for isolating the effect of wage inflation differentials that occur without markup adjustments from the effect of those occur concurrently with markup adjustments. From (11), $a_{1}>0$, as it captures the effect of volatility of wage inflation differentials not associated with markup adjustments and deviations from the LOOP for capital and imported intermediates. The coefficient $a_{2}$ captures the effect of volatility of wage inflation differentials associated with markup adjustments and deviations from the LOOP for capital and imported intermediates. Thus, the sign of $a_{2}$ depends on the correlation between wage inflation differentials and deviations from the LOOP for capital and imported intermediates.

In addition, we derive the second estimating equation from the contribution of wage inflation differentials to the variance of sector-specific RER depreciation in (12):

$$
v_{i}^{w}=b_{0}+b_{1} \gamma_{i}+u_{i},
$$

where $b_{1}=d v_{i}^{w} / d \gamma_{i}=\left[2 \gamma_{i}\left(\sigma_{i}^{w}\right)^{2}+\rho_{i}^{w h} \sigma_{i}^{w} \sigma_{i}^{h}-v_{i}^{w}\left(d\left(\sigma_{i}^{q}\right)^{2} / d \gamma_{i}\right)\right] /\left(\sigma_{i}^{q}\right)^{2}$. Hence, $b_{1}>0$ if $2 \gamma_{i}\left(\sigma_{i}^{w}\right)^{2}>$ $-\rho_{i}^{w h} \sigma_{i}^{w} \sigma_{i}^{h}+v_{i}^{w}\left(d\left(\sigma_{i}^{q}\right)^{2} / d \gamma_{i}\right)$. This inequality should hold if the wage inflation differential is so volatile that the effect of its variance multiplied with twice of the degree of nontradability dominates

other terms. For this reason, the second estimating equation identifies whether the change in sector-specific wages in the two countries is a channel through which the degree of nontradability 
influences volatility of sector-specific RER depreciation. A positive estimate of $b_{1}$ suggests that wage inflation differentials influence the movements of relative price of labor-intensive goods more than the movements of relative price of capital-intensive goods.

\section{The Empirics}

\subsection{Description of Data}

The real empirical challenge is to match, on a sector by sector basis, data for wages and prices across countries using the best quality and highest frequency series possible. After searching comprehensively, we arrive at two sets of sector pairs, 36 US-Canada sector pairs and 31 USGermany sector pairs.

The US-Canada sector pairs use monthly wage and consumer price index (CPI) series from 1991:1 to 2009:1. For both prices and wages, we obtain non seasonally adjusted data from the US Bureau of Labor Statistics (BLS) and Statistics Canada (CANSIM). The US-Canada exchange rate series is a monthly average from CANSIM.

The US-Germany sector pairs use quarterly wages and producer price index (PPI) series from 1995:1 to 2006:4. For Germany, we obtain non seasonally adjusted data from Statisches Bundesamt, Wiesbaden. We use the PPI, instead of CPI, in this case to expand sector coverage. This is equivalent to imposing an assumption that the distribution margin charged by US retailers is identical to that charged by German retailers in every sector.

Next, the data for the calculation of $\gamma_{i}$ are from the 2002 US Benchmark input-output (IO) table and the benchmark import matrix from the US Bureau of Economic Analysis (BEA). Let $x(i)$ denote the commodity code $x$ for input used in the production of good $i$ in the US input-output 
table. We calculate the parameters required for the calculation of $\gamma_{i}$ as follows.

(i) $\alpha_{i}$ is a share of employee compensation in total input cost for sector $i$.

$$
\alpha_{i}=\frac{V 001(i)}{T 005(i)+V 001(i)+V 002(i)+V 003(i)},
$$

where the code T005 is intermediate input cost, the code V001 is employee compensation, the code V002 is tax on production and imports taxes less subsidies, and the code V003 is the gross operating surplus.

(ii) $\alpha_{j}$ is the share of employee compensation in the input cost of all other sectors $j \neq i$.

$$
\alpha_{j}=\frac{\sum_{j \neq i} V 001(j)}{\sum_{j \neq i} T 005(j)+V 001(j)+V 002(j)+V 003(j)} .
$$

(iii) $\delta_{i}$ is the share of domestically intermediate input costs in total input cost for sector $i$. Let $I M(i)$ denote the value of imported intermediate input used in the production of good $i$ in the 2002 benchmark import matrix from the BEA. Then,

$$
\delta_{i}=\frac{T 005(i)-I M(i)}{T 005(i)+V 001(i)+V 002(i)+V 003(i)} .
$$

(iv) $\delta_{j}$ is the share of domestically intermediate input costs in total input cost for all other sectors $j \neq i$.

$$
\delta_{j}=\frac{\sum_{j \neq i} T 005(j)-I M(j)}{\sum_{j \neq i} T 005(j)+V 001(j)+V 002(j)+V 003(j)} .
$$




\subsection{Degree of Nontradability}

We report the degree of nontradability $\left(\gamma_{i}\right)$ and its components in Table 1 . Column 1 displays the sector codes from the US IO table. We rank the sectors by the degree of nontradability in column 2.

[Table 1 about here.]

The degree of nontradability varies from 13\% (cigarettes and tobacco products) to 59\% (commercial printing and recreation reading materials). It is $50 \%$ or higher than $50 \%$ in 17 out of 36 sectors. Its median, average and standard deviation are $45 \%, 49 \%$ and $11 \%$, respectively.

Next, we report the cost share of labor in the final production $\left(\alpha_{i}\right)$ and the cost share of labor in the production of domestic intermediate inputs $\left(\delta_{i} \alpha_{j}\right)$ in columns 3 and 4 of Table 1 . The cost share of labor in the final production varies from $5 \%$ to $38 \%$, and the cost share of labor in the production of domestic intermediate inputs varies from $7 \%$ to $24 \%$. Their average is $19 \%$ and $17 \%$, respectively. In addition, we find that in 16 sectors the cost share of labor in the production of intermediate inputs is higher than the cost share of labor in final production. This finding highlights the importance of labor costs in the entire process of production for our measure of nontradability.

However, the recent literature emphasizes the role of nontraded intermediate inputs as the cause of deviations from the LOOP. This approach classifies certain sectors as nontraded and measures their cost share in final production. For instance, Crucini, Telmer, and Zachariadis (2005) measure the cost share of nontraded intermediate inputs from the UK's input-output table. They classify the following sectors as nontraded goods: utilities, construction, distribution, hotels, catering, railways, road transport, sea transport, air transport, transport services, telecommunications, 
banking, finance, insurance, business services, education, health and other services. They found that the cost share of nontraded inputs in 53 sectors varies from $5 \%$ to $32 \%$, although their sector coverage is different from ours.

To compare our work to the literature, we employ the methodology in Crucini, Telmer, and Zachariadis (2005) to obtain the cost share of nontraded intermediate inputs from the US inputoutput table and report it in column 5 of Table 11 It varies from $7 \%$ to $39 \%$. Its average is $23 \%$, which is about half of the average degree of nontradability. Its median is also about half of the median degree of nontradability. For all except for one sector (gasoline) the cost share of nontraded intermediate inputs is lower than our degree of nontradability. The correlation is $48 \%$, indicating that the ranking of sectors based on these two measures is quite different. Although the least nontradable sectors according to our measure have the lowest share of nontraded input, the sector with the highest share of nontraded inputs is the third least nontradable. On the other hand, our most nontradable sectors have moderate shares of nontraded intermediate inputs.

\footnotetext{
${ }^{1}$ The following sectors in the US input-output table are classified as nontraded: wholesale trade; retail trade; air transportation; rail transportation; water transportation; truck transportation; transit and ground passenger transportation; pipeline transportation; scenic and sightseeing transportation and support activities; courier and messenger services; warehousing and storage; newspapers, books, and directories; software publishers; motion pictures and sound recordings; radio and television broadcasting; cable networks and program distribution; internet publishing and broadcasting; telecommunications; data processing services; other information services; monetary authorities, credit intermediation and related activities; securities, commodity contracts, investments, and related activities; insurance carriers and related services; funds, trusts, and other financial vehicles; real estate; owneroccupied dwellings; automotive equipment rental and leasing; consumer goods and general rentals; machinery and equipment rental and leasing; rights to nonfinancial intangible assets; legal services; accounting, tax preparation, bookkeeping, and payroll services; architectural, engineering, and related services; specialized design services; computer systems design and related services; management and technical consulting services; scientific research and development services; advertising and related services; other professional and technical services; management of companies and enterprises; employment services; travel arrangement and reservation services; all other administrative and support services; waste management and remediation services; educational services; ambulatory health care services; hospital care; nursing and residential care; social assistance; performing arts, spectator sports, and museums; amusements, gambling, and recreation; accommodation; food services and drinking places; automotive repair and maintenance; electronic, commercial, and household goods repair; personal and laundry services; religious, grantmaking, and social advocacy; civic, social, professional and similar organizations; private household services; federal government enterprises; state and local government enterprises; general federal defense government services; general federal nondefense government services; and general state and local government services.
} 
In addition, we compare our degree of nontradability with comparable measures in recent studies in Table2, In Panel A, we compare our nontradability with the share of nontraded inputs in Crucini et al. (2005) ${ }^{2}$ and the distribution margin in Crucini and Shintani (2008) $\mathrm{H}^{3}$ We rank sectors in this table by the degree of nontradability, from low to high. The cost share of nontraded inputs in Crucini et al. (2005) in column 2 ranges from 5\% to 15\%, while our degree of nontradability in column 1 ranges from $14 \%$ to $63 \%$. The average of our degree of nontradability and their cost share of nontraded inputs over the same set of sectors is $44 \%$ and $11 \%$, respectively. Since they do not consider labor in the final good production as a nontraded input, it is reasonable that their measure is lower than ours. However, our degree of nontradability is closer to the distribution margin in Crucini and Shintani (2008) in column 3. Although ours varies over a larger range than theirs, our average $(0.44)$ is quite close to theirs $(0.46)$.

Panel B compares our nontradability with the distribution margin in Burstein et al. (2003) 4 Their distribution margin is higher than our nontradability in all cases. This result is plausible since retailers can charge markup in addition to costs of distribution.

[Table 2 about here.]

\footnotetext{
${ }^{2}$ Crucini et al. (2005) derived the share of nontraded input from the 1988 input-output matrix for the U.K. Nontraded inputs are assumed to include: utilities, construction, distribution, hotels, catering, railways, road transport, sea transport, air transport, transport services, telecommunications, banking, finance, insurance, business services, education, health and other services.

${ }^{3}$ Crucini and Shintani (2008) constructed the distribution margin using the US National Income Product Account and the US inputoutput tables. Their distribution margin measures the difference between what final consumers pay and what producers receive.

${ }^{4}$ Burstein et al. (2003) constructed the distribution margin of data from the Economic Research Service, the US Department of Agriculture. They calculated the distribution margin as one minus the percentage of the retail price of a given product that is paid to the farmer.
} 


\subsection{Volatility of Real Exchange Rate Depreciation and Wage Inflation Differential}

Table 3 tabulates summary statistics of the volatility of RER depreciation and wage inflation differential. The volatility is measured by the variance of changes over various horizons. We report the average of all sectors in columns 1 and 2. The dispersion or the standard deviation across all sectors is in the last two columns.

[Table 3 about here.]

For the US-Canada sector pairs, month-to-month sector-specific RER depreciation is roughly as volatile as wage inflation differentials. However, sector-specific RER depreciation is much more volatile than wage inflation differentials over horizons longer than one month. Moreover, the dispersion of the variance of sector-specific RER depreciation is more than twice of that of wage inflation differentials over all horizons. We find a similar pattern for the US-Germany sector pairs. These statistics indicate that in addition to fluctuations of nominal exchange rate, nominal prices and nominal wages are not completely sticky even in a very short horizon.

Next, we report the time-series correlation between sector-specific RER depreciation and wage inflation differentials in Table 4. Evidently, the correlation is positive for all sector pairs and there is heterogeneity across sectors. Hence, we cannot attribute the correlation to fluctuations of nominal exchange rate. Moreover, the correlation is higher than $50 \%$ for one-third of US-Canada sector pairs, and three quarters of US-Germany sector pairs. Its median is $40 \%$ for US-Canada sector pairs and $92 \%$ for US-Germany sector pairs. When we extend the horizon of changes, the median correlation becomes even higher. In particular, over longer horizons the median correlation for US-Canada sector pairs varies from $49 \%$ to $78 \%$. For US-Germany sector pairs, the median 
correlation is higher than $90 \%$ for all horizons. Although the lowest correlation becomes negative when the horizon is longer, these negative correlations apply to only two sectors.

[Table 4 about here.]

Based on the high correlations in Table 4, we conjecture that wage inflation differentials likely account for a significant fraction of the variance of RER depreciation. We support this conjecture by the variance decomposition.

\subsection{Variance Decomposition Results}

Table 5 reports the summary statistics of the contribution of wage inflation differentials to the variance of sector-specific RER depreciation.

[Table 5 about here.]

The contribution of wage inflation differentials to the variance of sector-specific RER depreciation ranges from $0 \%$ to $72 \%$ for the US-Canada pairs, and $0 \%$ to $56 \%$ for the US-Germany pairs. For both US-Canada and US-Germany pairs, the median and average contribution is roughly $30 \%$. This finding is consistent with the positive and strong time-series correlation between sector-specific RER depreciation and wage inflation differential in Table 4.

Our finding is related to the recent study of product-level price data from the US and Canada by Gopinath, Gourinchas, Hsieh and Li (2010), who decompose the retail price into the wholesale cost and the retail markup. They found that the median contribution of wholesale cost to the variability of the relative retail price ranges from $55 \%$ in weekly frequency to $77 \%$ in quarterly frequency. However, the wholesale cost in their study includes both labor costs and costs of 
tradable inputs. This explains why their contribution of cost variability in the variability of the relative price is higher than the contribution of wage inflation differentials in our study.

Our result is different from the finding in studies of aggregate RERs, such as Engel (1999) and Betts and Kehoe (2006). The macro literature has found that movements of the US-Canada RER and the US-Germany RER are almost 100 percent driven by movements of the relative price of traded goods. However, our result does not necessarily contradict the macro literature. In theory, the RER depreciation in the macro literature is a weighted average of the sector-specific RER depreciation, and the weight is the share in consumption expenditure. If the sectors in which wage inflation differentials play a significant role in movements of the sector-specific RER depreciation occupy a very small expenditure share, then the nontraded component will not play an important role in fluctuations of the RER in aggregate. Nonetheless, aggregating the sector-specific RER depreciation into the country-level RER is beyond the scope of our study.

In the next subsection, we provide supportive evidence that our degree of nontradability can explain the observed heterogeneity in the variance of sector-specific RER depreciation and its decomposition.

\subsection{Estimation Results}

We report the estimation results for the regression equation (13) in Table (6), where numbers in the bracket below the coefficient estimates are standard errors. We employ three samples: US-Canada sector pairs in monthly frequency, US-Germany sector pairs in quarterly frequency, and pooled (US-Canada, US-Germany) sector pairs in quarterly frequency. In the case of pooled sample, we include the country-pair fixed effect and report clustered standard errors.

Table (6) provides evidence for the quadratic relationship between the degree of nontradability 
and the variance of sector-specific RER depreciation. The estimated coefficient of the squared degree of nontradability $\left(\hat{a_{1}}\right)$ is statistically significant and positive over a 24-month horizon for US-Canada pairs, and over 4-quarter and 8-quarter horizons for US-Germany pairs. As for the estimated coefficient of the level of nontradability $\left(\hat{a_{2}}\right)$, it is significantly negative over horizons longer than one month for US-Canada pairs, and over 4-quarter and 8-quarter horizons for USGermany pairs, implying a negative comovement between changes in the relative wage and those in the relative markup or deviations from the LOOP for capital and imported intermediates. The pooled sample regressions yield a similar set of results for 4-quarter and 8-quarter horizons. The adjusted- $R^{2}$ varies from 0.20 to 0.41 , suggesting that the estimation has considerable explanatory power, given that our estimating equation accounts for only one source of sectoral heterogeneity.

The quadratic relationship suggests that the positive effect of the degree of nontradability on the variance of sector-specific RER depreciation largely depends on the initial degree of nontradability. If the initial level of nontradability is above $-0.5 \hat{a}_{2} / \hat{a}_{1}$, then an increase in nontradability will increase the variance of sector-specific RER depreciation. If the initial level of nontradability is below $-0.5 \hat{a}_{2} / \hat{a}_{1}$, then an increase in nontradability will decrease the variance of sector-specific RER depreciation. Finally, if the initial level of nontradability is exactly $-0.5 \hat{a}_{2} / \hat{a}_{1}$, then an increase in nontradability will have no effects on the variance of the sector-specific RER depreciation. The threshold level of nontradability $\left(-0.5 \hat{a}_{2} / \hat{a}_{1}\right)$ also influences the quantitative effect of nontradability on the variance of sector-specific RER depreciation.

For instance, the threshold level of nontradability for US-Canada pairs over a 24-month horizon is 0.5174 . According to Table 1, 12 out of 36 sectors have a higher degree of nontradability than 0.5174. Suppose the degree of nontradability increases by one standard deviation, from 0.52 to 0.63. That increases the variance of US-Canada sector-specific RER depreciation by $0.89\left(0.63^{2}-\right.$ 
$\left.0.52^{2}\right)-0.86(0.11)=0.0180$, which is equivalent to 37 percent of its dispersion (in Table 3 ). For the US-Germany pairs, the threshold level of nontradability is 0.4891 and 0.5000 over 4 -quarter and 8-quarter horizons, respectively.

A one-standard deviation increase in the degree of nontradability from 0.52 to 0.63 increases the variance of US-Germany sector-specific RER depreciation by 0.0063 over a 4-quarter horizon and 0.0172 over an 8-quarter horizon, or 34 percent and 38 percent of its dispersion, respectively. Evidently, the quantitative effect of nontradability on the variance of sector-specific RER depreciation relative to its dispersion in our two samples, particularly over the same horizon, is remarkably close.

[Table 6 about here.]

Next, we report the estimation results for the regression equation (14) in Table (7). For both US-Canada pairs and US-Germany pairs, the degree of nontradability has a statistically significant and positive effect on the contribution of wage inflation differentials to the variance of sectorspecific RER depreciation over all horizons. A one-standard deviation increase in the degree of nontradability increases the contribution of wage inflation differentials to the variance of sectorspecific RER depreciation by 8\%-9\% for US-Canada sector pairs, and 8\%-11\% for US-Germany sector pairs. An alternative interpretation is that, a one percent increases in the degree of nontradability raises the contribution of wage inflation differentials to the sector-specific RER depreciation by roughly three quarters of a percent.

Similar pattern exists when we pool both samples together. This result provides supportive evidence that the degree of nontradability influences volatility of the sector-specific RER depreciation through fluctuations of sector-specific wages in the two countries. 
[Table 7 about here.]

As a sensitivity analysis, we replace our measure of nontradability with the cost share of nontraded intermediate inputs or $s_{i}$ in Table (1). The estimation results in this case are in Tables 8 and 9. We also found a quadratic relationship between the cost share of nontraded inputs and the variance of sector-specific RER depreciation. However, its threshold level is much lower than that in our benchmark specification, varying from $86 \%$ to $109 \%$ of its median. An increase in the cost share of nontraded inputs increases volatility of sector-specific RER depreciation of 17-29 sectors, depending on the time horizon.

In terms of magnitude, for US-Canada sector pairs the cost share of nontraded inputs has a smaller effect on the variance of sector-specific RER depreciation than the degree of nontradability. The threshold level of the cost share of nontraded inputs for a 24-month horizon is 0.2457. A onestandard deviation (0.0681) increase in the cost share of nontraded inputs from 0.25 raises the variance of sector-specific RER depreciation by 0.0093 . This is half of the effect of a one-standard deviation increase in the degree of nontradability from the level slightly higher than its threshold.

For the US-Germany sector pairs, the threshold level of the cost share of nontraded inputs is 0.2292 for a 4-quarter horizon and 0.2255 for a 8-quarter horizon. A one-standard deviation increase in the cost share of nontraded inputs from 0.25 raises the variance of sector-specific RER depreciation by 0.0126 over a 4-quarter horizon and 0.0301 over a 8-quarter horizon. These effects are roughly twice of the effect of a one-standard deviation increase in the degree of nontradability from the level slightly higher than its threshold level.

[Table 8 about here.]

Finally, in Table 9 we found no statistically significant relationship between the cost share 
of nontraded inputs and the contribution of wage inflation differentials to the variance of sectorspecific RER depreciation. In other words, increasing these nontraded inputs does not make wage inflation differentials become more accountable for a larger fraction of variability of the sectorspecific RER. Consequently, what drives the quadratic relationship between the cost share of nontraded inputs and the variance of sector-specific RER depreciation is either the costs of capital or the distribution markups or both. This finding complements studies that emphasizes the role of distribution margins by Burstein et al. (2003), Burstein et al. (2005) and Crucini et al. (2005).

[Table 9 about here.]

\section{Conclusion}

We propose that our measure of nontradability or the share of labor costs in total costs in the entire process of production is useful in explaining sectoral heterogeneity in the time-series variance of sector-specific RER depreciation. In the data we found that this measure of nontradability influences the variability of sector-specific RERs through exchange rate-adjusted wage inflation differentials.

Our findings have several implications for understanding of both sector-specific RERs and country-level RERs. A conventional interpretation of a large border effect, notably in Engel and Rogers (1996), on the deviations from the LOOP is that, the existence of border creates segmentation in goods markets and factor markets, thereby making possible the price stickiness and wage stickiness in the data observed. Our evidence on the importance of wage inflation differentials points to the role of wage stickiness, which exists in the presence of large labor market frictions that prevents labor from moving across countries and sectors. 
A useful extension is to study the role of wage stickiness and the degree of nontradability in the persistence of deviations from the LOOP. The effect of tradability on the persistence of productlevel RER depreciation has been recently explored by Cheung and Fujii (2008) using data for Japan. But they rely on a tradable-nontradable dichotomy in their classification of goods. They found no evidence that tradability influences the persistence of product-level RER depreciation. Our larger set of degree of nontradability can improve their analysis. Also, we can aggregate the sector-specific RER depreciation to study deviations of the RER from the purchasing power parity. Such aggregation can help us understand the effect of labor intensity on the RER dynamics.

In addition, we contribute to the growing literature that emphasizes the importance of labor market frictions in open economies, such as Kehoe and Ruhl (2009) and Mendoza, Tesar and Gorodnichenko (2008). The caveat is that, we highlight the importance of sectoral heterogeneity of labor market frictions rather than aggregate frictions. Our study also supplements the studies on wage stickiness in a closed-economy framework (Castellanos et al., 2004; Kahn, 1997; Liu and Phaneuf, 2007; Taylor, 1999).

\section{References}

Betts, C. M., and T. J. Kehoe (2006): "U.S. Real Exchange Rate Fluctuations and Relative Price Fluctuations," Journal of Monetary Economics, 53(7), 1297-1326.

Burstein, A., M. Eichenbaum, and S. Rebelo (2005): "Large Devaluations and the Real Exchange Rate," Journal of Political Economy, 113(4), 742-784.

Burstein, A., J. C. Neves, and S. Rebelo (2003): "Distribution Costs and Real Exchange Rate Dynamics during Exchange-Rate-Based Stabilizations," Journal of Monetary Economics, 
$50(6), 1189-1214$.

Castellanos, S. G., R. Garcia-Verdu, and D. S. Kaplan (2004): "Nominal Wage Rigidities in Mexico: Evidence from Social Security Records," Journal of Development Economics, $75(2), 507-533$.

Cheung, Y.-W., And E. FujiI (2008): "Deviations from the Law of One Price in Japan," CESIFO Working Paper, 2275.

Crucini, M. J., and M. Shintani (2008): "Persistence in law of one price deviations: Evidence from micro-data," Journal of Monetary Economics, 55(2), 629-644.

Crucini, M. J., C. I. Telmer, and M. Zachariadis (2005): "Understanding European Real Exchange Rates," American Economic Review, 95(3), 724-738.

Engel, C. (1999): "Accounting for U.S. Real Exchange Rate Changes," Journal of Political Economy, 107(3), 507-538.

Engel, C., And J. H. Rogers (1996): "How Wide Is the Border?," American Economic Review, $86(5), 1112-25$.

Ghironi, F., And M. J. Melitz (2005): "International Trade and Macroeconomic Dynamics with Heterogeneous Firms," Quarterly Journal of Economics, 120(3), 865-915.

Gopinath, G., P.-O. Gourinchas, C.-T. Hsieh, and N. Li (2010): "International Prices, Costs and Markup Differences," American Economic Review, 101(6), 2450-86.

Gorodnichenko, Y., E. Mendoza, and L. Tesar (2012): "The Finnish Great Depression: From Russia with love," American Economic Review, 101(4), 16191644. 
Kaнn, S. (1997): "Evidence of Nominal Wage Stickiness from Microdata," American Economic Review, 87(5), 993-1008.

Kehoe, T. J., and K. J. Ruhl (2009): "Sudden Stops, Sectoral Reallocations, and the Real Exchange Rate," Journal of Development Economics, 89(2), 235-249.

Liu, Z., And L. Phaneuf (2007): "Technology Shocks and Labor Market Dynamics: Some Evidence and Theory," Journal of Monetary Economics, 54(8), 2534-2553.

MendozA, E. G. (2000): "On the Stability of Variance Decompositions of the Real Exchange Rate Across Exchange-Rate Regimes: Evidence from Mexico and the United States," NBER Working Papers, 7768.

NaknoI, K. (2008): "Real Exchange Rate Fluctuations, Endogenous Tradability and Exchange Rate Regimes," Journal of Monetary Economics, 55(3), 645-663.

TAYlor, J. B. (1999): "Staggered Price and Wage Setting in Macroeconomics," in Handbook of Macroeconomics, ed. by J. B. Taylor, and M. Woodford, pp. 1009-1050. Elsevier. 
Table 1: Degree of nontradability $\left(\gamma_{i}\right)$, its components and share of nontraded intermediate inputs $\left(s_{i}\right)$

\begin{tabular}{|c|c|c|c|c|c|}
\hline & $(1)$ & $(2)$ & $(3)$ & $(4)$ & $(5)$ \\
\hline Sector & IO Code & $\gamma_{i}$ & $\alpha_{i}$ & $\delta_{i} \alpha_{j}$ & $s_{i}$ \\
\hline Cigarettes & 3122 & 0.13 & 0.05 & 0.07 & 0.07 \\
\hline Tobacco products & 3122 & 0.13 & 0.05 & 0.07 & 0.07 \\
\hline Gasoline & 2110 & 0.26 & 0.07 & 0.15 & 0.39 \\
\hline Household cleaning products & 3256 & 0.32 & 0.11 & 0.15 & 0.26 \\
\hline New and used motor vehicles & 3361 & 0.37 & 0.09 & 0.20 & 0.12 \\
\hline Sports vehicles including bicycles & 3361 & 0.37 & 0.09 & 0.20 & 0.12 \\
\hline Alcoholic beverages & 3121 & 0.37 & 0.10 & 0.19 & 0.20 \\
\hline Alcoholic beverages away from home & 3121 & 0.37 & 0.10 & 0.19 & 0.20 \\
\hline Beverages and beverage materials & 3121 & 0.37 & 0.10 & 0.19 & 0.20 \\
\hline Nonalcoholic beverages and beverage materials & 3121 & 0.37 & 0.10 & 0.19 & 0.20 \\
\hline Fruits and melons, fresh and dry vegetables & 1110 & 0.39 & 0.12 & 0.18 & 0.31 \\
\hline Meat, poultry and fish & 1120 & 0.39 & 0.06 & 0.23 & 0.18 \\
\hline Pulp, paper and allied products & 3221 & 0.42 & 0.17 & 0.17 & 0.25 \\
\hline Primary nonferrous metals & $331 \mathrm{~B}$ & 0.46 & 0.17 & 0.19 & 0.22 \\
\hline Textile products and apparel & 3140 & 0.47 & 0.20 & 0.18 & 0.16 \\
\hline Appliances & 3352 & 0.47 & 0.20 & 0.17 & 0.18 \\
\hline Petroleum and coal products manufacturing & 2121 & 0.48 & 0.32 & 0.14 & 0.28 \\
\hline Communication and related equipment & $334 \mathrm{~A}$ & 0.49 & 0.20 & 0.18 & 0.33 \\
\hline Medical care commodities & 3391 & 0.49 & 0.29 & 0.13 & 0.22 \\
\hline Motor vehicle maintenance and repair & 8111 & 0.50 & 0.29 & 0.13 & 0.29 \\
\hline Footwear & 3150 & 0.50 & 0.22 & 0.17 & 0.27 \\
\hline Chemicals and allied products & 3251 & 0.50 & 0.14 & 0.23 & 0.33 \\
\hline Newsprint & 3222 & 0.50 & 0.20 & 0.19 & 0.22 \\
\hline Food away from home & 3110 & 0.51 & 0.14 & 0.24 & 0.25 \\
\hline Dishes and flatware & 3322 & 0.52 & 0.30 & 0.14 & 0.21 \\
\hline Nonmetallic mineral product manufacturing & 3270 & 0.52 & 0.26 & 0.16 & 0.28 \\
\hline Fabricated structural metal products & $331 \mathrm{~A}$ & 0.53 & 0.20 & 0.20 & 0.31 \\
\hline Plastic products & 3260 & 0.54 & 0.25 & 0.17 & 0.22 \\
\hline Rubber and rubber products & 3260 & 0.54 & 0.25 & 0.17 & 0.22 \\
\hline Transportation equipment & $336 \mathrm{~A}$ & 0.54 & 0.23 & 0.19 & 0.22 \\
\hline Hides, skins, leather and related products & 3160 & 0.55 & 0.25 & 0.18 & 0.23 \\
\hline Machinery and equipment, except electrical & 3333 & 0.55 & 0.27 & 0.17 & 0.25 \\
\hline Private transportation & 4850 & 0.58 & 0.38 & 0.12 & 0.26 \\
\hline Public transportation & 4850 & 0.58 & 0.38 & 0.12 & 0.26 \\
\hline Commercial printing & 3230 & 0.59 & 0.33 & 0.15 & 0.26 \\
\hline Recreational reading materials & 3230 & 0.59 & 0.33 & 0.15 & 0.26 \\
\hline
\end{tabular}

Note: Matching between sectors and IO codes is not one-to-one; some sectors have multiple subcategories. 
Table 2: Comparison of degree of nontradability $\left(\gamma_{i}\right)$ with the share of nontraded Inputs in Crucini et al. (2005) $\left(s_{i}^{C}\right)$, the distribution margin in crucini and shintani $(2008)\left(d_{i}^{C}\right)$ and the distribution margin in burstein et al. (2003) $\left(d_{i}^{B}\right)$.

\begin{tabular}{|c|c|c|c|}
\hline & (1) & $(2)$ & $(3)$ \\
\hline \multicolumn{4}{|l|}{ Panel A. } \\
\hline Sector & $\gamma_{i}$ & $s_{i}^{C}$ & $d_{i}^{C}$ \\
\hline Tobacco products & 0.13 & 0.05 & 0.39 \\
\hline New and used motor vehicles & 0.37 & 0.09 & \\
\hline Alcoholic beverages & 0.37 & 0.10 & \\
\hline Pulp, paper and allied products & 0.42 & 0.14 & \\
\hline Textile products and apparel & 0.47 & 0.10 & 0.52 \\
\hline Appliances & 0.47 & 0.14 & \\
\hline Communication and related equipment & 0.49 & 0.12 & \\
\hline Medical care commodities & 0.49 & & 0.36 \\
\hline Footwear & 0.50 & 0.09 & \\
\hline Rubber, rubber products and plastic products & 0.54 & 0.13 & \\
\hline Transportation equipment & 0.54 & 0.15 & \\
\hline Private transportation & 0.58 & & 0.55 \\
\hline \multicolumn{4}{|l|}{ Panel B. } \\
\hline Sector & $\gamma_{i}$ & $d_{i}^{B}$ & \\
\hline Fresh fruits* & 0.39 & 0.82 & \\
\hline Fresh vegetables* & 0.39 & 0.79 & \\
\hline Meat products* & 0.39 & 0.64 & \\
\hline Poultry* & 0.39 & 0.59 & \\
\hline
\end{tabular}

Notes: * denotes sectors classified by Burstein et al. (2003). His classification disaggregates goods to more detailed categories than ours. Column 1 is our measure of nontradability. In Panel A, column 2 is from Table A1 in the Data Appendix in Crucini et al. (2005), and column 3 is from Table 2 on page 634 in Crucini and Shintani (2008). In Panel B, column 2 is from Table 2 on page 1200 in Burstein et al. (2003). 
Table 3: Summary statistics of variance of sector-specific RER depreciation and wage inflation differential

\begin{tabular}{lllll}
\hline \hline & \multicolumn{2}{c}{ Average of all sectors } & \multicolumn{2}{c}{ Dispersion across all sectors } \\
\hline Number of lags & $\begin{array}{l}\text { RER } \\
\text { depreciation }\end{array}$ & $\begin{array}{l}\text { Wage inflation } \\
\text { differential }\end{array}$ & $\begin{array}{l}\text { RER } \\
\text { depreciation }\end{array}$ & $\begin{array}{l}\text { Wage inflation } \\
\text { differential }\end{array}$ \\
\hline A. US-Canada pairs & & & & \\
1 & 0.0016 & 0.0012 & 0.0026 & 0.0006 \\
3 & 0.0052 & 0.0033 & 0.0069 & 0.0016 \\
6 & 0.0110 & 0.0061 & 0.0139 & 0.0031 \\
12 & 0.0191 & 0.0074 & 0.0265 & 0.0029 \\
24 & 0.0336 & 0.0129 & 0.0491 & 0.0059 \\
& & & & \\
B. US-Germany pairs & & & & \\
2 & 0.0049 & 0.0032 & 0.0053 & 0.0035 \\
4 & 0.0104 & 0.0061 & 0.0110 & 0.0051 \\
8 & 0.0214 & 0.0111 & 0.0186 & 0.0008 \\
& 0.0533 & 0.0283 & 0.0449 & 0.0030 \\
\hline
\end{tabular}

Note: The measure of dispersion is the cross-sectional standard deviation. 
Table 4: Summary statistics of correlation between sector-specific RER depreciation and wage inflation differential

\begin{tabular}{lcccc}
\hline \hline Number of lags & Minimum & Maximum & Median & Average \\
\hline A. US-Canada pairs & & & & \\
1 & 0.08 & 0.70 & 0.40 & 0.42 \\
3 & 0.13 & 0.80 & 0.49 & 0.53 \\
6 & 0.12 & 0.87 & 0.62 & 0.62 \\
12 & 0.10 & 0.87 & 0.66 & 0.66 \\
24 & -0.07 & 0.92 & 0.78 & 0.75 \\
& & & & \\
B. US-Germany pairs & & & & \\
1 & 0.12 & 0.98 & 0.92 & 0.77 \\
2 & 0.02 & 0.99 & 0.93 & 0.79 \\
4 & -0.14 & 0.99 & 0.96 & 0.85 \\
8 & -0.47 & 0.99 & 0.96 & 0.87 \\
\hline
\end{tabular}


Table 5: Summary statistics of contribution of wage inflation differentials to the variance of sectorspecific RER depreciation

\begin{tabular}{lcclll}
\hline \hline Number of lags & Min & Max & Median & Average & Standard deviation \\
\hline \multirow{2}{*}{ A. US-Canada pairs } & & & & & \\
1 & 0.00 & 0.51 & 0.28 & 0.27 & 0.15 \\
3 & 0.00 & 0.48 & 0.28 & 0.27 & 0.14 \\
6 & 0.00 & 0.49 & 0.30 & 0.29 & 0.14 \\
12 & 0.00 & 0.49 & 0.27 & 0.26 & 0.12 \\
24 & 0.00 & 0.72 & 0.32 & 0.30 & 0.15 \\
& & & & & \\
B. US-Germany pairs & & & & & \\
1 & -0.03 & 0.53 & 0.33 & 0.29 & 0.16 \\
2 & 0.00 & 0.52 & 0.33 & 0.31 & 0.14 \\
4 & -0.01 & 0.55 & 0.34 & 0.33 & 0.14 \\
8 & -0.02 & 0.56 & 0.34 & 0.33 & 0.13 \\
& & & & & \\
\hline
\end{tabular}


Table 6: Dependent variable: Variance of sector-specific RER depreciation

A. US-Canada pairs

\begin{tabular}{llllll}
\hline Dependent variable & lag $=1$ & lag $=3$ & lag $=6$ & lag $=12$ & lag $=24$ \\
\hline$\gamma_{i}^{2}$ & 0.02 & 0.08 & 0.18 & 0.33 & 0.89 \\
& $(0.02)$ & $(0.06)$ & $(0.12)$ & $(0.24)$ & $(0.42)^{* *}$ \\
$\gamma_{i}$ & -0.02 & -0.09 & -0.19 & -0.34 & -0.86 \\
Constant & -0.02 & $(0.05)^{*}$ & $(0.10)^{*}$ & $(0.19)^{*}$ & $(0.32)^{* *}$ \\
& 0.01 & 0.03 & 0.06 & 0.10 & 0.23 \\
Adjusted $R^{2}$ & $(0.00)^{* * *}$ & $(0.01)^{* * *}$ & $(0.02)^{* * *}$ & $(0.03)^{* * *}$ & $(0.06)^{* * *}$ \\
Sample size & 0.16 & 0.20 & 0.17 & 0.13 & 0.24 \\
& 36 & 36 & 36 & 36 & 36
\end{tabular}

B. US-Germany pairs

\begin{tabular}{lllll}
\hline & lag $=1$ & lag $=2$ & lag $=4$ & lag $=8$ \\
\hline$\gamma_{i}^{2}$ & 0.04 & 0.12 & 0.45 & 1.04 \\
& $(0.06)$ & $(0.12)$ & $(0.18)^{* *}$ & $(0.46)^{* *}$ \\
$\gamma_{i}$ & -0.06 & -0.15 & -0.46 & -1.04 \\
Constant & $(0.05)$ & $(0.09)$ & $(0.14)^{* * *}$ & $(0.37)^{* * *}$ \\
& 0.02 & 0.05 & 0.13 & 0.30 \\
Adjusted $R^{2}$ & $(0.01)^{* *}$ & $(0.02)^{* * *}$ & $(0.03)^{* * *}$ & $(0.07)^{* * *}$ \\
Sample size & 0.23 & 0.25 & 0.41 & 0.32 \\
& 31 & 31 & 31 & 31
\end{tabular}

C. Pooled sample

\begin{tabular}{lllll}
\hline & lag $=1$ & lag $=2$ & lag $=4$ & lag $=8$ \\
\hline$\gamma_{i}^{2}$ & 0.06 & 0.15 & 0.37 & 0.94 \\
& $(0.02)$ & $(0.03)$ & $(0.05)^{*}$ & $(0.07)^{* *}$ \\
$\gamma_{i}$ & -0.08 & -0.17 & -0.38 & -0.92 \\
Constant & $(0.02)$ & $(0.02)^{*}$ & $(0.06)^{*}$ & $(0.08)^{*}$ \\
& 0.03 & 0.05 & 0.11 & 0.27 \\
Adjusted $R^{2}$ & $(0.00)^{*}$ & $(0.00)^{* *}$ & $(0.01)^{*}$ & $(0.02)^{*}$ \\
Sample size & 0.25 & 0.25 & 0.20 & 0.34 \\
& 67 & 67 & 67 & 67 \\
& & & &
\end{tabular}

Notes: $\gamma_{i}$ denotes the degree of nontradability. $* * *, * *$, and $* *$ denote statistical significance at 1 percent, 5 percent, and 10 percent, respectively. In the estimation using the pooled sample, we include the country-pair fixed effect and report clustered standard errors. 
Table 7: Dependent variable: Contribution of wage inflation differentials to the variance of sectorspecific RER depreciation

\begin{tabular}{|c|c|c|c|c|c|}
\hline \multicolumn{6}{|l|}{ A. US-Canada pairs } \\
\hline Dependent variable & $\operatorname{lag}=1$ & $\operatorname{lag}=3$ & $\operatorname{lag}=6$ & $\operatorname{lag}=12$ & $\operatorname{lag}=24$ \\
\hline \multirow[t]{2}{*}{$\gamma_{i}$} & 0.81 & 0.77 & 0.80 & 0.73 & 0.91 \\
\hline & $(0.18)^{* * *}$ & $(0.16)^{* * *}$ & $(0.15)^{* * *}$ & $(0.13)^{* * *}$ & $(0.16)^{* * *}$ \\
\hline \multirow[t]{2}{*}{ Constant } & -0.10 & -0.08 & -0.07 & -0.07 & -0.11 \\
\hline & $(0.08)$ & $(0.07)$ & $(0.07)$ & $(0.06)$ & $(0.07)$ \\
\hline Adjusted $R^{2}$ & 0.37 & 0.40 & 0.44 & 0.47 & 0.47 \\
\hline Sample size & 36 & 36 & 36 & 36 & 36 \\
\hline \multicolumn{6}{|l|}{ B. US-Germany pairs } \\
\hline & $\operatorname{lag}=1$ & $\operatorname{lag}=2$ & $\operatorname{lag}=4$ & $\operatorname{lag}=8$ & \\
\hline \multirow[t]{2}{*}{$\gamma_{i}$} & 0.77 & 0.92 & 1.04 & 0.99 & \\
\hline & $(0.27)^{* * *}$ & $(0.20)^{* * *}$ & $(0.18)^{* * *}$ & $(0.16)^{* * *}$ & \\
\hline \multirow[t]{2}{*}{ Constant } & -0.06 & -0.11 & -0.14 & -0.12 & \\
\hline & $(0.12)$ & $(0.09)$ & $(0.08)$ & $(0.08)$ & \\
\hline Adjusted $R^{2}$ & 0.20 & 0.40 & 0.52 & 0.55 & \\
\hline Sample size & 31 & 31 & 31 & 31 & \\
\hline \multicolumn{6}{|l|}{ C. Pooled sample } \\
\hline & $\operatorname{lag}=1$ & $\operatorname{lag}=2$ & $\operatorname{lag}=4$ & $\operatorname{lag}=8$ & \\
\hline \multirow[t]{2}{*}{$\gamma_{i}$} & 0.77 & 0.85 & 0.85 & 0.94 & \\
\hline & $(0.00)^{* * *}$ & $(0.06)^{* *}$ & $(0.15)$ & $(0.04)^{* *}$ & \\
\hline \multirow[t]{2}{*}{ Constant } & -0.06 & -0.07 & -0.06 & -0.10 & \\
\hline & $(0.01)^{* * *}$ & $(0.03)$ & $(0.07)$ & $(0.02)$ & \\
\hline Adjusted $R^{2}$ & 0.31 & 0.44 & 0.53 & 0.52 & \\
\hline Sample size & 67 & 67 & 67 & 67 & \\
\hline
\end{tabular}

Notes: $\gamma_{i}$ denotes the degree of nontradability. $* * * * *$, and $* *$ denote statistical significance at 1 percent, 5 percent, and 10 percent, respectively. In the estimation using the pooled sample, we include the country-pair fixed effect and report clustered standard errors. 
Table 8: Dependent variable: Variance of sector-specific RER depreciation

A. US-Canada pairs

\begin{tabular}{llllll}
\hline Dependent variable & lag $=1$ & lag =3 & lag =6 & lag =12 & lag $=24$ \\
\hline$s_{i}^{2}$ & 0.18 & 0.44 & 0.77 & 1.16 & 2.53 \\
& $(0.06)^{* * *}$ & $(0.15)^{* * *}$ & $(0.31)^{* *}$ & $(0.61)^{*}$ & $(1.07)^{* *}$ \\
$s_{i}$ & -0.07 & -0.20 & -0.36 & -0.57 & -1.30 \\
& $(0.03)^{* * *}$ & $(0.07)^{* * *}$ & $(0.14)^{* *}$ & $(0.27)^{* *}$ & $(0.48)^{* *}$ \\
Constant & 0.01 & 0.03 & 0.05 & 0.08 & 0.19 \\
& $(0.00)^{* * *}$ & $(0.01)^{* * *}$ & $(0.02)^{* * *}$ & $(0.03)^{* * *}$ & $(0.05)^{* * *}$ \\
Adjusted $R^{2}$ & 0.18 & 0.16 & 0.12 & 0.07 & 0.16 \\
Sample size & 36 & 36 & 36 & 36 & 36
\end{tabular}

B. US-Germany pairs

\begin{tabular}{lllll}
\hline & lag $=1$ & lag $=2$ & lag $=4$ & lag $=8$ \\
\hline$s_{i}^{2}$ & 0.46 & 0.89 & 1.68 & 3.77 \\
& $(0.12)^{* * *}$ & $(0.26)^{* * *}$ & $(0.42)^{* * *}$ & $(1.06)^{* * *}$ \\
$s_{i}$ & -0.19 & -0.38 & -0.77 & -1.70 \\
& $(0.05)^{* * *}$ & $(0.12)^{* * *}$ & $(0.20)^{* * *}$ & $(0.49)^{* * *}$ \\
Constant & 0.02 & 0.05 & 0.10 & 0.23 \\
& $(0.00)^{* * *}$ & $(0.01)^{* * *}$ & $(0.02)^{* * *}$ & $(0.06)^{* * *}$ \\
Adjusted $R^{2}$ & 0.36 & 0.27 & 0.32 & 0.26 \\
Sample size & 31 & 31 & 31 & 31
\end{tabular}

C. Pooled sample

\begin{tabular}{lllll}
\hline & lag $=1$ & lag =2 & lag $=4$ & lag $=8$ \\
\hline$s_{i}^{2}$ & 0.46 & 0.84 & 1.40 & 3.14 \\
& $(0.01)^{* *}$ & $(0.07)^{* *}$ & $(0.26)$ & $(0.63)$ \\
$s_{i}$ & -0.20 & -0.37 & -0.66 & -1.49 \\
& $(0.01)^{* *}$ & $(0.01)^{* *}$ & $(0.10)^{*}$ & $(0.21)^{*}$ \\
Constant & 0.02 & 0.05 & 0.09 & 0.22 \\
& $(0.01)^{* *}$ & $(0.00)^{* *}$ & $(0.01)^{*}$ & $(0.01)^{* *}$ \\
Adjusted $R^{2}$ & 0.26 & 0.21 & 0.19 & 0.27 \\
Sample size & 67 & 67 & 67 & 67 \\
& & & &
\end{tabular}

Notes: $s_{i}$ denotes the share of nontraded intermediate inputs. $* * *, * *$, and ${ }^{* *}$ denote statistical significance at 1 percent, 5 percent, and 10 percent, respectively. In the estimation using the pooled sample, we include the country-pair fixed effect and report clustered standard errors. 
Table 9: Dependent variable: Contribution of wage inflation differentials to the variance of sectorspecific RER depreciation

\begin{tabular}{|c|c|c|c|c|c|}
\hline \multicolumn{6}{|l|}{ A. US-Canada pairs } \\
\hline Dependent variable & $\operatorname{lag}=1$ & $\operatorname{lag}=3$ & $\operatorname{lag}=6$ & $\operatorname{lag}=12$ & $\operatorname{lag}=24$ \\
\hline \multirow[t]{2}{*}{$s_{i}$} & 0.54 & 0.50 & 0.40 & 0.37 & 0.44 \\
\hline & $(0.36)$ & $(0.33)$ & $(0.34)$ & $(0.30)$ & $(0.37)$ \\
\hline \multirow[t]{2}{*}{ Constant } & 0.14 & 0.16 & 0.19 & 0.17 & 0.20 \\
\hline & $(0.09)$ & $(0.08)^{*}$ & $(0.08)^{* *}$ & $(0.07)^{* *}$ & $(0.09)$ \\
\hline Adjusted $R^{2}$ & 0.03 & 0.03 & 0.01 & 0.02 & 0.01 \\
\hline Sample size & 36 & 36 & 36 & 36 & 36 \\
\hline \multicolumn{6}{|l|}{ B. US-Germany pairs } \\
\hline & $\operatorname{lag}=1$ & $\operatorname{lag}=2$ & $\operatorname{lag}=4$ & $\operatorname{lag}=8$ & \\
\hline \multirow[t]{2}{*}{$s_{i}$} & -0.30 & -0.15 & 0.05 & 0.11 & \\
\hline & $(0.45)$ & $(0.39)$ & $(0.39)$ & $(0.37)$ & \\
\hline \multirow[t]{2}{*}{ Constant } & 0.36 & 0.34 & 0.32 & 0.30 & \\
\hline & $(0.11)^{* * *}$ & $(0.10)^{* * *}$ & $(0.10)^{* * *}$ & $(0.09)^{* * *}$ & \\
\hline Adjusted $R^{2}$ & -0.02 & -0.03 & -0.03 & -0.03 & \\
\hline Sample size & 31 & 31 & 31 & 31 & \\
\hline \multicolumn{6}{|l|}{ C. Pooled sample } \\
\hline & $\operatorname{lag}=1$ & $\operatorname{lag}=2$ & $\operatorname{lag}=4$ & $\operatorname{lag}=8$ & \\
\hline \multirow[t]{2}{*}{$s_{i}$} & 0.14 & 0.15 & 0.23 & 0.29 & \\
\hline & $(0.40)$ & $(0.27)$ & $(0.16)$ & $(0.17)$ & \\
\hline \multirow[t]{2}{*}{ Constant } & 0.26 & 0.27 & 0.28 & 0.26 & \\
\hline & $(0.09)$ & $(0.06)$ & $(0.04)^{*}$ & $(0.04)^{*}$ & \\
\hline Adjusted $R^{2}$ & 0.01 & 0.01 & 0.08 & 0.03 & \\
\hline Sample size & 67 & 67 & 67 & 67 & \\
\hline
\end{tabular}

Notes: $s_{i}$ denotes the share of nontraded intermediate inputs. $* * * * *$, and $* *$ denote statistical significance at 1 percent, 5 percent, and 10 percent, respectively. In the estimation using the pooled sample, we include the country-pair fixed effect and report clustered standard errors. 